\title{
Acute toxicity study of a polysaccharide based hydrogel from linseed for potential use in drug delivery system
}

\author{
Muhammad Tahir Haseeb ${ }^{1 *}$, Sajid Bashir ${ }^{1}$, Muhammad Ajaz Hussain ${ }^{2}$, Muhammad Umer Ashraf ${ }^{1}$, \\ Alia Erum¹, Muhammad Naeem-ul-Hassan²
}

\author{
${ }^{1}$ Department of Pharmaceutics, Faculty of Pharmacy, University of Sargodha, Sargodha, Pakistan, ${ }^{2}$ Department of Chemistry, \\ University of Sargodha, Sargodha, Pakistan
}

\begin{abstract}
Linseed hydrogel (LSH) was evaluated by acute toxicity for its potential application in oral drug delivery design. White albino mice and rabbits were divided in four groups (I-IV) and different doses of LSH (1, 2 and $5 \mathrm{~g} / \mathrm{kg}$ body weight) were given except to the control group (I) that was left untreated. Rabbits were monitored for eye irritation, acute dermal toxicity and primary dermal irritation, whereas, body weight, food and water consumption, hematology and clinical-biochemistry, gross necropsy and histopathology of vital organs were scrutinized in mice. LSH was considered safe after eye irritation test as no adverse signs or symptoms were seen in the eye. In dermal toxicity and irritation study, skin of treated rabbits was found normal in color without any edema or erythema. After oral administration, there was no sign of any abnormalities in treated group animals (II-IV). The hematology and clinical biochemistry of treated group animals was comparable with the control group. Histopathology of vital organs has not shown any lesion or abnormalities. In the light of these outcomes, it can be concluded that LSH is not a hazardous biomaterial and could be incorporated as an excipient in oral and dermal preparations.
\end{abstract}

Keywords: Linseed hydrogel. Acute toxicity. Hematology. Clinical biochemistry. Polysaccharide

\section{INTRODUCTION}

Over the past few decades, enormous progress has figured out in the invention and development of biomaterials for various biomedical applications (Hoffman, 2000). Among these, polysaccharides based polymeric biomaterials have drawn appreciable attention of the biomedical scientists due to their biocompatibility (Dang, Leong, 2006), biodegradability (Jain, Gupta, Jain, 2007), bioavailability (Mizrahy, Peer, 2012), ease and versatility in drug designing and development (Zhang, Wardwell, Bader, 2013; Hussain et al., 2011; Hussain et al., 2009). These properties also make such naturally occurring polysaccharides an integral part of many drug delivery systems (Iqbal et al., 2011; Xu et al., 2015; Muhammad et al., 2016; Ashraf et al., 2017).

Due to immense importance of polysaccharides as a drug delivery system, it is necessary to evaluate and

\footnotetext{
*Correspondence: M. T. Haseeb. Department of Pharmaceutics, Faculty of Pharmacy, University of Sargodha, Sargodha 40100, Pakistan. Tel:

+ 92 3004474058. E-mail address: mtahir212@yahoo.com
}

establish the safety profile of these materials. For this purpose, toxicological evaluation is carried out to ensure their diverse and extensive biomedical applications. Depending upon the nature, duration of treatment, route of administration and chemical composition of the materials, various types (acute, sub-acute, sub-chronic and chronic) of toxicity studies are carried out.

Recently, toxicological studies of polysaccharides extracted from Plantago ovata (Erum et al., 2015), Mangifera indica (Amien et al., 2015), Araucaria heterophylla (Divvela, Duppala, Kolapalli, 2016), Curcuma longa (Velusami et al., 2013) have been conducted by different researchers. Additionally, chitosan and its derivatives are extensively used in various biomedical applications and evaluated through toxicity studies (Kean, Thanou, 2010; Hu et al., 2011).

Flax (Linum usitatissimum L.) is cultivated to get fibers and seeds. Flaxseeds/linseeds are the rich source of oil, protein and carbohydrates and have many applications in food industry (Oomah, 2001). Linseed is rich in polysaccharides which are present in the seed coat and mainly composed of rhamnogalacturonan and 
arabinoxylan (Oomah et al., 1995; Qian et al., 2012). Linseed polysaccharides can be easily separated using hot water extraction method (Haseeb et al., 2016). In our previous work, linseed hydrogel (LSH) has shown high swelling capacity, stimuli responsive swelling-deswelling behavior and remarkable potential as a sustained release material for oral drug delivery system (Haseeb et al., 2016; Haseeb et al., 2017). Due to widespread potential and application of LSH in a various dosage forms, it is necessary to investigate the safety profile of LSH. For this purpose, acute toxicity study of LSH was carried out to establish its safety profile for safe administration and development of various drug delivery systems.

\section{MATERIAL AND METHODS}

\section{Isolation of linseed hydrogel}

Linseed hydrogel (LSH) was isolated by adopting the already reported method (Haseeb et al., 2016). Briefly, linseeds were thoroughly washed with deionized water to remove dust particles. Clean seeds were soaked in deionized water for $48 \mathrm{~h}$. Subsequently, seeds were heated at $80^{\circ} \mathrm{C}$ for $30 \mathrm{~min}$. Mucilage was excreted from the seeds and separated using nylon mesh. Extracted mucilage were defatted with $n$-hexane and washed with deionized water. After centrifugation of the mucilage, LSH were settled down and separated, dried at $60^{\circ} \mathrm{C}$ for $48 \mathrm{~h}$, passed through sieve no. 60 and stored in air tight container in desiccator.

\section{Animals}

Swiss albino mice (25-31 g) and albino rabbits (1115-1225 g) of either sex bred were obtained from the animal house of University of Sargodha, Sargodha, Pakistan and thoroughly examined for any symptoms of sickness and anomalies. Animals were divided into four groups (group I-IV) $(n=5)$ as described in Table I.

Animals were kept in clean stainless steel cages in a $12 \mathrm{~h}$ photoperiod (light on at 06:00 and off at 18:00) at 22 to $25^{\circ} \mathrm{C}$ and $40-70 \%$ humidity. Mice and rabbits were fed with standard laboratory diet and had free access to ordinary tap water. All tests conformed to the Good
Laboratory Practice (GLP) regulations as described by United States Food and Drug Administration (USFDA). Procedures adopted for acute toxicity studies were in accordance with the guidelines of Organization for Economic Co-operation and Development (OECD) and National Institute of Health for the care and use of laboratory animals. The study protocol was approved by Pharmacy Research Ethics Committee of University of Sargodha, Sargodha, Pakistan.

\section{Acute oral toxicity}

Acute oral toxicity study of LSH was executed in Swiss albino mice following the OECD guidelines for analysis of chemicals toxicity. At the instigation of the study, the weight variation of animals involved was kept minimal and should be $< \pm 20 \%$ of the mean weight (Lina, Bar, 2004). After overnight fasting, LSH mixed with food was orally administered to mice of groups II, III and IV as single oral dose of 1,2 and $5 \mathrm{~g} / \mathrm{kg}$ body weight (bw), respectively (Table I). The dose of LSH was according to criteria for excipient toxicity testing and was more than estimated daily intake of excipient (George, Shipp, 2000). The mice were observed in detail for any indication of toxic effect, mortality, ill health and any reaction to treatment such as changes in fur, skin, mucus membranes, eyes, behavior pattern, tremors, salivation, diarrhea, sleep and coma within the first six hours after the treatment and daily for a period of 14 days.

\section{Primary eye irritation}

This study was carried out in five Albino rabbits. Animals were thoroughly examined for any abnormalities according to Draize scale for eye lesions (Draize, 1944). A suspension of LSH in water $(10 \mathrm{mg} / 10 \mathrm{~mL})$ was dropcasted into the conjunctival sac of the right eye of each rabbit. Upper and lower lids were kept together with fingers for some time in order to reduce the risk of any loss of the test material. For comparison, the left eye of each rabbit was remained untreated and used as a control. After LSH administration, eyes were examined after 1, 24,48 , and $72 \mathrm{~h}$ for any lacrimation, redness, swelling and

TABLE I - Group scheme for acute oral toxicity study of LSH in mice

\begin{tabular}{cccc}
\hline Group I & Group II & Group III & Group IV \\
\hline $\begin{array}{c}\text { Control given only standard } \\
\text { diet }\end{array}$ & $\begin{array}{c}\text { Treated with LSH (1 g/kg bw) } \\
\text { ground and mixed with diet }\end{array}$ & $\begin{array}{c}\text { Treated with LSH (2 g/kg bw) } \\
\text { ground and mixed with diet }\end{array}$ & $\begin{array}{c}\text { Treated with LSH (5 g/kg bw) } \\
\text { ground and mixed with diet }\end{array}$ \\
\hline
\end{tabular}

bw: body weight 
corneal and pupil irritation. Primary eye irritation score was determined with maximum mean total score (MMTS) as described by Kay and Calandra (Kay, Calandra, 1962). Ocular lesion was classified according to the Draize scale for scoring eye lesions (Draize, 1944).

\section{Acute dermal toxicity}

Five white albino rabbits were used for acute dermal toxicity testing. Rabbits were thoroughly examined for health and skin abnormalities before and after removal of hair from the back of these rabbits. Thick paste of ground LSH $(500 \mathrm{mg})$ in deionized water was prepared and applied on a 4 ply gauze pad ( 4 in $\times 4$ in). Prepared gauze pad was placed on the skin of rabbit and wrapped with Micropore ${ }^{\mathrm{TM}}$ tape (3 inch wide) to avoid displacement of the pad. Rabbits were allowed to move freely in their respective cages and observed them for any behavioral changes for next few hours. After $24 \mathrm{~h}$, the pads were carefully removed from the skin and the site of application was observed for any color changes in skin or presence of rashes etc. Rabbits were kept under observation for next 14 days and observed for weight gain or loss, mortality, sign of behavioral changes, any changes in skin, fur, eyes and mucous membrane, diarrhea, salivation, coma, convulsions and tremors (Saiyad et al., 2015).

\section{Primary dermal irritation study}

Five adult, young and non-pregnant female albino rabbits were selected to carry out primary dermal irritation study. Hairs from the back of rabbits were removed by clipping the dorsal and trunk area. Skin of rabbits was examined for abnormalities before and after the removal of hairs and no pre-existing irritation or lesion on the skin was observed. To apply test material on the skin, LSH (500 mg) was moistened with deionized water to make a thick paste and applied on an area of approximately $6 \mathrm{~cm}^{2}$. Test area was covered with gauze pad and protected from dislocation with the help of suitable semi-occlusive dressing. After $4 \mathrm{~h}$, dressing was removed and test site was gently cleaned from residual test material, observed and score was recorded at 1, 24, 48 and $72 \mathrm{~h}$ after removal of dressing according to the Draize scoring system (Kay, Calandra, 1962). Irritancy was classified by adding the average edema and erythema scores for 1, 24, 48 and $72 \mathrm{~h}$ scoring intervals and dividing by the number of evaluation intervals (Saiyad et al., 2015). The calculated Primary Dermal Irritation Index (PDII) was classified according to the descriptive rating (Sreejayan et al., 2010).

\section{Body weight}

The body weights of mice were recorded before treatment, at day 1, 2, 3, 5, 7 and 14 of treatment. Mean body weight was calculated for each group.

\section{Food and water consumption}

The amount of food and water consumed by mice before treatment, at day 1, 2, 3, 5, 7 and 14 was measured and compared with control to observe the influence of LSH intake on these parameters. These day intervals were selected to observe and record a more precise and accurate values.

\section{Hematology and clinical biochemistry}

On day 15, blood samples were collected from the overnight (about $12 \mathrm{~h}$ ) fasted mice of each group into lithium heparin or $\mathrm{K}_{2}$-EDTA containing tubes. Blood samples were analyzed for hemoglobin, white blood cells count, red blood cells count, platelets, monocytes, neutrophils, lymphocytes, mean corpuscular volume $(\mathrm{MCV})$, mean corpuscular hemoglobin $(\mathrm{MCH})$ and mean corpuscular hemoglobin concentration (MCHC).

Blood plasma was also analyzed for alanine aminotransferase (ALT), aspartate aminotransferase (AST), creatinine, urea, uric acid, cholesterol and triglycerides.

\section{Gross necropsy and histopathology}

At the end of day 14, mice of each group were sacrificed. Gross necropsy of all vital organs (heart, liver, lung, kidney, stomach, intestine and spleen) was carried out. Organs were weighed and relative organ body weight was calculated. Organs were preserved in neutral buffered formalin $(10 \% \mathrm{v} / \mathrm{v})$. Tissues were sliced to $4-5 \mu \mathrm{m}$ thickness and histopathology was performed after staining with hematoxylin-eosin.

\section{Statistics}

The difference among the numerical values of control group and different treated groups were analyzed through one way analysis of variance (ANOVA) followed by Student's t-test using statistical analyses software, Minitab 11. One way ANOVA (Turkeys multiple comparison test) and probability value $<0.05$ was considered as statistically significant. The level of significance was set at $p<0.05$. All values were expressed as mean \pm S.D. 


\section{RESULTS AND DISCUSSION}

\section{Acute oral toxicity study in mice}

In acute toxicity study, a single oral dose of LSH was given to three groups (group II, III and IV) of male albino mice (Table I). At the end of day 14, all animals were alive, active and healthy. No other abnormalities were seen including behavioral changes, pharmacological adverse effects and gross toxicities during the 14 day study period. Food intake was less after day 1 as compared to remaining days (slight decrease in the body weight in the animal of treated groups was observed at day 1 which might be due to less food intake as LSH intake may feel the fullness of stomach). Results have indicated that the acute oral lethal dose $\left(\mathrm{LD}_{50}\right)$ of LSH is greater than $5 \mathrm{~g} / \mathrm{kg}$ bw for male albino mice.

\section{Primary eye irritation}

To find out the primary eye irritation, LSH suspension was instilled in the eye of rabbit. Corneal opacity, iritis, conjunctivitis and severity (MMTS) of treated eye was monitored. No sign of any abnormality was seen during 72 $\mathrm{h}$ in all groups and assigned 0 score except group II. Eye of one animal in group II exhibited conjunctival discharge that was cured within $24 \mathrm{~h}$. The score was assigned 2.0 and 1.0 after $1 \mathrm{~h}$ and $24 \mathrm{~h}$, respectively according to Kay and Calandra eye irritation scale (Kay, Calandra, 1962). Severity of the condition (MMTS) in group II was 0.67 and 0.33 after $1 \mathrm{~h}$ and $24 \mathrm{~h}$, respectively. No other adverse effects and symptoms were seen. Therefore, the conjunctival discharge was classified as accidental and overall LSH was found to be nonirritating to the eye.

\section{Acute dermal toxicity}

Acute dermal toxicity study was carried out in male albino rabbits. Single topical application of three different doses of LSH (1, 2 and $5 \mathrm{~g} / \mathrm{kg}$ bw) were applied on three groups of rabbits. All animals survived, gained weight and did not find any other clinical findings or abnormalities during the whole course of study. It is concluded that the acute dermal toxic dose was greater than $5 \mathrm{~g} / \mathrm{kg}$ body weight.

\section{Primary dermal irritation study}

Primary dermal irritation study was conducted to evaluate the potential of LSH irritancy on a single topical application. No erythema or edema was found on the skin of treated animal over the course of 14 days. Primary dermal irritation index was calculated as 0.0 indicating the LSH as a non-irritating material to the skin.

\section{Body weight study}

Results of body weight study are summarized in Table II. It was noted that there are gradually increase in mean body weight of the control group during the whole study period. A decrease in body weight of group II, group III and group IV was observed at day 1 while weight gain in treated mice was noticed at day 7 and 14 .

\section{Food and water consumption}

Food and water intake of each group was measured on day 1,2, 3, 5, 7 and 14. Results have indicated that there was no significant difference in food and water consumption between control group animals and treated animals during the whole study period with exception of day 1 (Table II). A significant decrease in the food and water intake was noted for group I, group II and group III on day 1 which was normalized as the study proceeded.-

\section{Hematology and clinical biochemistry}

Hematological parameters of each group were found to be normal and they are comparable with the control group (group I) as mentioned in Table III. Liver, kidney and lipid profiles were also determined and results are found to be normal. All values are comparable with the animals of control group as mentioned in Table IV.

\section{Gross necropsy and histopathology}

Macroscopic analysis of the mice of each group was performed and did not find LSH-related abnormalities (Table V). All vital organs were remove and weighed separately. Results have indicated that no significant variations in relative organ body weight of all vital organs when compared with the mice of control group.

\section{CONCLUSION}

Considering the outcomes of different parameters investigated during acute toxicology study, it could be deduced that LSH is a safe material for use as an excipient in oral drug delivery system. LSH has met and fulfilled the safety criteria of all parameters investigated in acute toxicity evaluation and regarded as a safe material for biomedical applications. $\mathrm{LD}_{50}$ for $\mathrm{LSH}$ was estimated to be 
TABLE II - Observations of body weight, water and food intake study of LSH

\begin{tabular}{|c|c|c|c|c|}
\hline Observations & Group I & Group II & Group III & Group IV \\
\hline Signs of illness & NIL & NIL & NIL & NIL \\
\hline \multicolumn{5}{|l|}{ Body weight (g) } \\
\hline Pretreatment & $26.4 \pm 2.2$ & $28.8 \pm 1.8$ & $26.1 \pm 2.2$ & $27.7 \pm 1.5$ \\
\hline Day 1 & $26.5 \pm 1.4$ & $28.7 \pm 1.5$ & $26.0 \pm 1.9$ & $27.4 \pm 3.5$ \\
\hline Day 2 & $27.6 \pm 1.2$ & $29.1 \pm 1.9$ & $26.2 \pm 1.1$ & $27.5 \pm 3.5$ \\
\hline Day 3 & $28.0 \pm 1.8$ & $29.8 \pm 1.1$ & $26.5 \pm 0.9$ & $27.7 \pm 3.5$ \\
\hline Day 5 & $28.4^{*} \pm 2.7$ & $30.1 \pm 2.2$ & $27.2 \pm 2.0$ & $28.8^{*} \pm 3.5$ \\
\hline Day 7 & $28.5^{*} \pm 2.4$ & $30.4 * \pm 1.8$ & $27.6^{*} \pm 2.8$ & $29.4 * \pm 2.5$ \\
\hline Day 14 & $28.8^{*} \pm 2.0$ & $30.8 * \pm 2.8$ & $28.4 * \pm 2.0$ & $29.6^{*} \pm 1.8$ \\
\hline \multicolumn{5}{|l|}{ Water intake (mL) } \\
\hline Pretreatment & $10.4 \pm 1.0$ & $12.2 \pm 0.5$ & $11.1 \pm 2.1$ & $11.7 \pm 1.5$ \\
\hline Day 1 & $10.8 \pm 1.5$ & $12.4 \pm 1.5$ & $11.6 \pm 1.5$ & $12.3 \pm 1.7$ \\
\hline Day 2 & $11.5 \pm 1.1$ & $12.6 \pm 0.5$ & $12.0 \pm 2.1$ & $12.6 \pm 1.1$ \\
\hline Day 3 & $12.8 \pm 0.8$ & $12.5 \pm 1.3$ & $12.3 \pm 1.8$ & $12.7 \pm 1.1$ \\
\hline Day 5 & $13.1^{*} \pm 1.8$ & $13.3 \pm 1.5$ & $12.8^{*} \pm 1.0$ & $12.9 \pm 0.7$ \\
\hline Day 7 & $13.0^{*} \pm 2.0$ & $13.7 * \pm 2.0$ & $13.0 * \pm 2.5$ & $13.0 \pm 2.3$ \\
\hline Day 14 & $13.2^{*} \pm 1.5$ & $13.9 * \pm 1.5$ & $13.2 * \pm 1.5$ & $13.2 * \pm 2.5$ \\
\hline \multicolumn{5}{|l|}{ Food intake (g) } \\
\hline Pretreatment & $3.4 \pm 1.0$ & $3.1 \pm 1.5$ & $3.6 \pm 2.1$ & $3.8 \pm 1.6$ \\
\hline Day 1 & $2.7 \pm 1.5$ & $2.4 \pm 2.1$ & $1.8^{*} \pm 1.1$ & $1.1 * \pm 1.7$ \\
\hline Day 2 & $3.2 \pm 1.9$ & $2.7 \pm 2.1$ & $2.3^{*} \pm 0.7$ & $2.0 * \pm 2.1$ \\
\hline Day 3 & $3.8 \pm 1.0$ & $2.9 \pm 1.1$ & $3.0 \pm 1.2$ & $2.3 * \pm 1.3$ \\
\hline Day 5 & $3.6 \pm 1.3$ & $3.5 \pm 1.4$ & $3.2 \pm 1.6$ & $3.2 \pm 0.7$ \\
\hline Day 7 & $4.0 \pm 1.0$ & $4.0 \pm 1.9$ & $3.8 \pm 0.5$ & $3.6 \pm 0.9$ \\
\hline Day 14 & $3.8 \pm 1.5$ & $3.8 \pm 1.3$ & $4.3 \pm 2.1$ & $4.2 \pm 1.1$ \\
\hline
\end{tabular}

Body weight, water and food intake are expressed as mean \pm S.D. ${ }^{*} P<0.05$ as significant difference when compared to control.

TABLE III - Biochemical blood analysis of control and LSH treated mice

\begin{tabular}{lcccc}
\hline Hematology & Group I & Group II & Group III & Group IV \\
\hline $\mathrm{Hb}(\mathrm{g} / \mathrm{dL})$ & $11.6 \pm 0.8$ & $12.1 \pm 1.6$ & $13.7 \pm 1.6$ & $13.5 \pm 1.4$ \\
$\mathrm{WBCs}\left(10^{3} / \mu \mathrm{L}\right)$ & $4.2 \pm 0.3$ & $5.1 \pm 0.4$ & $5.9 \pm 1.2$ & $6.5 \pm 0.5$ \\
$\mathrm{RBCs}\left(10^{6} / \mu \mathrm{L}\right)$ & $8.28 \pm 0.23$ & $8.39 \pm 0.45$ & $8.32 \pm 0.35$ & $8.15 \pm 0.23$ \\
Platelets $\left(10^{3} / \mu \mathrm{L}\right)$ & $549.7 \pm 2.9$ & $667.2 \pm 3.9$ & $678.6 \pm 5.5$ & $709.6 \pm 4.1$ \\
Monocytes $(\%)$ & $2.1 \pm 0.02$ & $2.3 \pm 0.01$ & $2.5 \pm 0.01$ & $2.2 \pm 0.02$ \\
Neutrophils $(\%)$ & $12.8 \pm 0.5$ & $13.5 \pm 0.3$ & $12.9 \pm 0.9$ & $13.8 \pm 0.02$ \\
Lymphocytes $(\%)$ & $83.3 \pm 2.1$ & $82.3 \pm 1.5$ & $84.6 \pm 2.1$ & $82.9 \pm 1.3$ \\
$\mathrm{MCV}$ & $45.8 \pm 1.5$ & $45.9 \pm 2.1$ & $51.4 \pm 1.4$ & $53.5 \pm 1.4$ \\
$\mathrm{MCH}$ & $14.5 \pm 0.5$ & $16.0 \pm 0.8$ & $15.7 \pm 1.0$ & $14.4 \pm 1.2$ \\
$\mathrm{MCHC}(\mathrm{g} / \mathrm{dL})$ & $28.7 \pm 0.3$ & $30.4 \pm 0.7$ & $29.6 \pm 1.5$ & $31.6 \pm 1.1$ \\
\hline
\end{tabular}

MCV: mean corpuscular volume, MCH: mean corpuscular hemoglobin, MCHC: mean corpuscular hemoglobin concentration. All values are expressed as mean \pm S.D. 
TABLE IV - Liver, kidney and lipid profile of mice treated with LSH

\begin{tabular}{lcccc}
\hline Biochemical analysis & Group I & Group II & Group III & Group IV \\
\hline ALT (IU/L) & $54 \pm 5.3$ & $70 \pm 3.2$ & $58 \pm 5.2$ & $66 \pm 2.1$ \\
AST (IU/L) & $134 \pm 8.3$ & $145 \pm 6.1$ & $176 \pm 7.1$ & $185 \pm 5.1$ \\
Creatinine (mg/dL) & $0.43 \pm 0.02$ & $0.42 \pm 0.01$ & $0.35 \pm 0.04$ & $0.38 \pm 0.02$ \\
Urea (mg/dL) & $62 \pm 2.3$ & $53 \pm 4.2$ & $48 \pm 4.2$ & $59 \pm 3.4$ \\
Uric acid (mg/dL) & $5.6 \pm 0.2$ & $4.5 \pm 0.05$ & $4.6 \pm 0.1$ & $4.8 \pm 0.1$ \\
Cholesterol (mg/dL) & $147 \pm 7.2$ & $136 \pm 2.3$ & $108 \pm 1.1$ & $116 \pm 5.2$ \\
Triglyceride (mg/dL) & $132 \pm 9.4$ & $110 \pm 2.3$ & $115 \pm 5.4$ & $87 \pm 4.8$ \\
\hline
\end{tabular}

ALT: alanine aminotransferase, AST: aspartate aminotransferase. All values are expressed as mean \pm S.D.

TABLE V - Absolute mean organ weight ( $\mathrm{g}$ ) of mice after oral administration of LSH

\begin{tabular}{lcccc}
\hline Organ & Group I & Group II & Group III & Group IV \\
\hline Heart & $0.66 \pm 0.05$ & $0.58 \pm 0.03$ & $0.57 \pm 0.05$ & $0.53 \pm 0.01$ \\
Liver & $6.44 \pm 0.37$ & $6.15 \pm 0.22$ & $5.52 \pm 0.14$ & $5.70 \pm 0.32$ \\
Lung & $0.54 \pm 0.12$ & $0.63 \pm 0.11$ & $0.67 \pm 0.23$ & $0.51 \pm 0.11$ \\
Kidney & $0.98 \pm 0.05$ & $1.08 \pm 0.07$ & $0.88 \pm 0.05$ & $1.52 \pm 0.02$ \\
Stomach & $1.05 \pm 0.18$ & $1.79 \pm 0.1$ & $1.38 \pm 0.4$ & $1.6 \pm 0.20$ \\
Spleen & $0.63 \pm 0.12$ & $0.55 \pm 0.01$ & $0.61 \pm 0.03$ & $0.60 \pm 0.12$ \\
\hline
\end{tabular}

All values are expressed as mean \pm S.D.

higher than $5 \mathrm{~g} / \mathrm{kg}$ bw and to find out $\mathrm{LD}_{50}$ more precisely, further investigations are recommended.

\section{ACKNOWLEDGEMENT}

M. T. Haseeb gratefully acknowledges the financial support provided by Higher Education Commission (HEC) of Pakistan under "Indigenous $5000 \mathrm{PhD}$ fellowship" program.

\section{REFERENCES}

Amien AI, Fahmy SR, Abd-Elgleel FM, Elaskalany SM. Renoprotective effect of Mangifera indica polysaccharides and silymarin against cyclophosphamide toxicity in rats. J Basic Appl Zoology 2015;72:154-162.

Ashraf MU, Hussain MA, Muhammad G, Haseeb MT, Bashir S, Hussain SZ, et al. A superporous and superabsorbent glucuronoxylan hydrogel from Quince (Cydonia oblanga): Stimuli responsive swelling, on-off switching and drug release. Int J Biol Macromol. 2017;95:138-144.

Dang JM, Leong KW. Natural polymers for gene delivery and tissue engineering. Adv Drug Deliv Rev. 2006;58(4):487-499.
Divvela HND, Duppala L, Kolapalli VRM. Isolation and acute oral toxicity studies of Araucaria heterophylla novel natural polysaccharide gum in albino mice. World J Pharm Pharm Sci. 2016;5(10):702-711.

Draize JH. Methods for the study of irritation and toxicity of substances applied topically to the skin and mucous membranes. J Pharmacol Exp Ther. 1944;82(3):377-390.

Erum A, Bashir S, Saghir S, Tulain UR, Saleem U, Nasir M, et al. Acute toxicity studies of a novel excipient arabinoxylan isolated from Ispaghula (Plantago ovata) husk. Drug Chem Toxicol. 2015;38(3):300-305.

George DJ, Shipp AM. Exposure assessment. In: Weiner Ml, Kotkoskie LA, editor. Excipient toxicity and safety. New York: Marcel Dekker; 2000. p. 283-303.

Haseeb MT, Hussain MA, Bashir S, Ashraf MU, Ahmad N. Evaluation of superabsorbent linseed-polysaccharides as a novel stimuli-responsive oral sustained release drug delivery system. Drug Dev Ind Pharm. 2017;43(3):409-420. 
Haseeb MT, Hussain MA, Yuk SH, Bashir S, Nauman M. Polysaccharides based superabsorbent hydrogel from Linseed: Dynamic swelling, stimuli responsive on-off switching and drug release. Carbohydr Polym. 2016;136:750-756.

Hoffman AS. Hydrogels for biomedical applications. Adv Drug Deliv Rev. 2000;54(1):3-12.

Hu YL, Qi W, Han F, Shao JZ, Gao JQ. Toxicity evaluation of biodegradable chitosan nanoparticles using a zebrafish embryo model. Int J Nanomed. 2011;6:3351-3359.

Hussain MA, Badshah M, Iqbal MS, Tahir MN, Tremel W, Bhosale SV, et al. HPMC-salicylate conjugates as macromolecular prodrugs: design, characterization and nanorods formation. J Polym Sci A Polym Chem. 2009;47(16):42024207.

Hussain MA, Hassan Z, Haseeb MT, Iqbal MS, Sher M, Tahir $\mathrm{MN}$, et al. Fabrication of potential macromolecular prodrugs of aspirin and diclofenac with dextran. Pak J Pharm Sci. 2011;24(4):575-581.

Iqbal MS, Akbar J, Hussain MA, Saghir S, Sher M. Evaluation of hot-water extracted arabinoxylans from ispaghula seeds as drug carriers. Carbohydr Polym. 2011;83(3):1218-1225.

Jain A, Gupta Y, Jain SK. Perspectives of biodegradable natural polysaccharides for site specific drug delivery to the colon. $\mathrm{J}$ Pharm Pharm Sci. 2007;10(1):86-128.

Kay JH, Calandra JC. Interpretation of eye irritation tests. J Soc Cosmet Chem. 1962;13(6):281-289.

Kean T, Thanou M. Biodegradation, biodistribution and toxicity of chitosan. Adv Drug Deliv Rev. 2010;62(1):3-11.

Lina BAR, Bar A. Subchronic oral toxicity studies with $\alpha$-cyclodextrin in rats. Regul Toxicol Pharmacol. 2004;39(1):1426.

Mizrahy S, Peer D. Polysaccharides as building blocks for nanotherapeutics. Chem Soc Rev. 2012;41(7):2623-2640.
Muhammad G, Hussain MA, Ashraf MU, Haseeb MT, Hussain SZ, Hussain I. Polysaccharide based superabsorbent hydrogel from Mimosa pudica: Swelling-deswelling and drug release. RSC Adv. 2016;6:23310-23317.

Oomah BD, Kenaschuk EO, Cui W, Mazza G. Variation in the composition of water-soluble polysaccharides in flaxseed. J Agric Food Chem. 1995;43(6):1484-1488

Oomah BD. Flaxseed as functional food source. J Sci Food Agric. 2001;81(9):889-894.

Qian KY, Cui SW, Wu Y, Goff HD. Flaxseed gum from flaxseed hulls: Extraction, fractionation, and characterization. Food Hydrocolloids. 2012;28(2):275-283.

Saiyad ZM, Sengupta K, Krishnaraju AV, Trimurtula G, Lau FC, Lugo JP. Safety and toxicological evaluation of Meratrim ${ }^{\circledR}$ : An herbal formulation for weight management. Food Chem Toxicol. 2015;78:122-129.

Sreejayan N, Marone PA, Lau FC, Yasmin T, Bagchi M, Bagchi D. Safety and toxicological evaluation of a novel chromium (III) dinicocysteinate complex. Toxicol Mech Methods. 2010;20(6):321-333.

Velusami CC, Boddapati SR, Srinivasa SH, Richard EJ, Joseph JA, Balasubramanian M, et al. Safety evaluation of turmeric polysaccharide extract: Assessment of mutagenicity and acute oral toxicity. BioMed Res Int. 2013;2013:158348.

Xu W, He X, Zhong M, Hu X, Xiao Y. A novel pH-responsive hydrogel based on natural polysaccharides for controlled release of protein drugs. RSC Adv. 2015;5:3157-3167.

Zhang N, Wardwell PR, Bader RA. Polysaccharide-based micelles for drug delivery. Pharmaceutics. 2013;5(2):329-352.

Received for publication on $08^{\text {th }}$ August 2017 Accepted for publication on $29^{\text {th }}$ October 2017 